\section{Eotaxin-3 as a Biomarker of Activity in Established Eosinophilic Granulomatosis with Polyangiitis}

\section{To the Editor:}

Eosinophilic granulomatosis with polyangiitis (EGPA) is a rare antineutrophil cytoplasmic antibody-associated vasculitis affecting small to medium vessels ${ }^{1,2}$. The majority of patients with EGPA respond to glucocorticoids \pm immunosuppressive agents ${ }^{3}$, though a significant proportion of them develop relapses and may require biologic treatment ${ }^{4}$. Novel biomarkers of disease activity for EGPA are needed because the clinical value of eosinophil count, serum IgE, erythrocyte sedimentation rate (ESR), and $\mathrm{C}$-reactive protein (CRP) in treated patients is low ${ }^{5}$. Eotaxin-3 is an eotactic chemokine that induces chemotaxis and activation of eosinophilic granulocytes in vitro, and may be involved in the pathogenesis of EGPA. Polzer, et al suggested that elevated eotaxin-3 expression was associated with high disease activity in $\mathrm{EGPA}^{6}$, while Dejaco, et al proposed that eotaxin-3 levels could not reliably discriminate between active and inactive disease in established $\mathrm{EGPA}^{7}$. In our current study, we investigated the clinical utility of eotaxin-3 as a possible biomarker of EGPA relapse.

A total of 38 patients with EGPA ( 27 women and 11 men at a mean age

Table 1. Clinical characteristic of patients with EGPA. Values are $\mathrm{n}(\%)$ unless otherwise specified.

\begin{tabular}{lcc}
\hline Clinical Characteristics & Activity, $\mathrm{n}=9$ & Remission, $\mathrm{n}=32$ \\
\hline Women & $8(88.9)$ & $21(65.6)$ \\
Age, yrs, mean \pm SD & $54.4 \pm 5.8$ & $56.0 \pm 12.7$ \\
Asthma & $9(100)$ & $30(93.8)$ \\
Constitutional symptoms & $8(88.9)$ & $28(87.5)$ \\
Arthralgia/myalgia & $9(100)$ & $25(78.1)$ \\
Skin & $6(66.7)$ & $18(56.3)$ \\
Peripheral neuropathy & $8(88.9)$ & $24(75.0)$ \\
Pulmonary disease & $7(77.8)$ & $18(56.3)$ \\
Heart & $3(33.3)$ & $7(21.9)$ \\
Gastrointestinal tract & $0(0)$ & $2(6.3)$ \\
Kidney & $1(11.1)$ & $9(28.1)$ \\
ENT & $7(77.8)$ & $29(90.6)$ \\
MPO-ANCA & $5(55.6)$ & $12(37.5)$ \\
BVAS, median (range) & $12(4-21)$ & 0 \\
Glucocorticoids & $6(66.7)$ & $32(100)$ \\
Immunosuppressive agents & $3(33.3)$ & $15(46.9)$ \\
\multicolumn{1}{c}{ Azathioprine, $\mathrm{n}$} & 2 & 11 \\
$\quad$ Methotrexate, $\mathrm{n}$ & 1 & 4 \\
\hline
\end{tabular}

EGPA: eosinophilic granulomatosis with polyangiitis; MPO: myeloperoxidase; ANCA: antineutrophil cytoplasmic antibodies; BVAS: Birmingham Vasculitis Activity Score. of $55.7 \pm 11.5 \mathrm{yrs}$ ) were enrolled in our study and underwent 41 laboratory tests. Additional visits in 3 patients were analyzed as independent cases. There were only 3 patients who had no history of treatment while all other patients were treated with glucocorticoids (Table 1). Vasculitis flares were observed in 9 visits (21.9\%). Activity of vasculitis was evaluated using the Birmingham Vasculitis Activity Score (BVAS) ${ }^{8}$. Worsening asthma and/or rhinosinusitis without other organ involvement was not sufficient to classify a patient as having active EGPA. Serum eotaxin-3 and interleukin (IL)-6 were analyzed by ELISA (R\&D Systems) ${ }^{6}$.

Laboratory variables were compared using the Mann-Whitney U test. The correlations between eotaxin-3 level and other laboratory tests were evaluated by the Spearman rho test. The association between biomarkers and disease activity was studied by multivariate logistic regression analysis, with $\mathrm{p}$ value $<0.05$ considered as statistical significance.

Vasculitis flares were associated with a modest but statistically significant increase in ESR, serum CRP level, and absolute eosinophil count. However, the difference in ESR lost significance in the multivariate model (Table 2). Median serum IL-6 levels were comparable in patients with remission and active EGPA. Serum eotaxin-3 levels varied widely both in patients in remission and those with vasculitis flares, while median values were almost identical in the 2 groups. Moreover, percentages of patients with different serum eotaxin-3 concentrations $(<80 \mathrm{pg} / \mathrm{ml}, 80-200 \mathrm{pg} / \mathrm{ml}$, and $>200 \mathrm{pg} / \mathrm{ml}$ ) were similar in remission and exacerbation of vasculitis. Serum eotaxin-3 levels did not correlate with ESR $(r=0.15)$, CRP $(r=$ $-0.02)$, absolute eosinophil count $(r=0.08)$, and serum IL-6 $(r=0.02)$. Eotaxin-3 levels were variable even in 3 untreated patients with EGPA (57.3 $\mathrm{pg} / \mathrm{ml}, 195.3 \mathrm{pg} / \mathrm{ml}$, and $365.0 \mathrm{pg} / \mathrm{ml}$ ).

A vasculitis flare can be easily established in a patient with EGPA who develops new major BVAS items. However, it may be a challenge to define disease activity in a patient who presents with isolated worsening of asthma and/or rhinosinusitis, constitutional symptoms, or myalgia/arthralgia. Moreover, deterioration of heart failure or kidney dysfunction in a patient with systemic vasculitis can be related to the natural evolution of organ damage or can be induced by external factors. Therefore, it does not always imply vasculitis exacerbation. The previous attempts to develop reliable biomarkers to measure EGPA activity were unsuccessful ${ }^{5}$. In our current study, we did not confirm the clinical utility of serum eotaxin-3 levels, which varied widely in the same range both in patients in remission and those with vasculitis flare, and did not correlate with the standard biomarkers such as absolute eosinophil count, ESR, and CRP. Moreover, the highest serum eotaxin-3 levels (> $200 \mathrm{pg} / \mathrm{ml}$ ) in 5 of 7 patients were not associated with any other evidence for activity of vasculitis. Almost all our patients received treatment with glucocorticoids \pm immunosuppressive agents. Therefore, serum eotaxin-3 level is not useful as a longitudinal biomarker of vasculitis flares.

In the previous studies, it was suggested that serum eotaxin-3 levels could discriminate EGPA from a broad spectrum of rheumatic diseases ${ }^{6,9}$ Eotaxin-3 was also a reliable biomarker for active EGPA. At a cutoff value

Table 2. Serum eotaxin-3 and other biomarker levels. Values are median (range) unless otherwise specified.

\begin{tabular}{|c|c|c|c|c|c|}
\hline $\begin{array}{l}\text { Eotaxin-3, pg/ml } \\
\text { Eotaxin-3, n (\%) }\end{array}$ & $107.6(54.6-356)$ & $98.2(58.8-402)$ & 0.68 & 0.68 & - \\
\hline$<80 \mathrm{pg} / \mathrm{ml}$ & $12(37.5)$ & $2(22.2)$ & - & - & - \\
\hline $80-200 \mathrm{pg} / \mathrm{ml}$ & $15(46.7)$ & $5(55.6)$ & - & - & - \\
\hline$>200 \mathrm{pg} / \mathrm{ml}$ & $5(15.6)$ & $2(22.2)$ & - & - & - \\
\hline $\mathrm{CRP}, \mathrm{mg} / \mathrm{l}$ & $2.13(0-5.85)$ & $0(0-2.71)$ & $<0.01$ & 0.01 & 0.02 \\
\hline Eosinophil count, $\times 10^{9} / 1$ & $1.17(0.24-2.53)$ & $0.28(0-0.48)$ & $<0.01$ & 0.02 & 0.05 \\
\hline
\end{tabular}

IL-6: interleukin 6; ESR: erythrocyte sedimentation rate; CRP: C-reactive protein. 
of $80 \mathrm{pg} / \mathrm{ml}$, its sensitivity and specificity reached $87.5 \%$ and $98.6 \%$, respectively ${ }^{9}$. In a multicenter study, in 25 patients with established EGPA, serum levels of TARC/CCL17, eotaxin-3, IgG4, and IgG4:IgG ratio did not differentiate active disease and remission ${ }^{8}$. Our data also suggest that glucocorticoids and immunosuppressive medications may modify serum eotaxin-3 levels and eosinophil counts independent of disease activity, and the frequent use of glucocorticoids in EGPA argues against a significant involvement for these biomarkers.

Our study has some limitations. Similar to the previous studies, the sample size was small. However, there was no reason to expect different results in the larger or longitudinal (with serial tests in the same group of patients) study, given a wide variability of serum eotaxin-3 levels and significant overlap between active and inactive EGPA. Almost all our patients had established EGPA and were treated with glucocorticoids. Given the rarity of disease, it was difficult to recruit a sufficient number of patients with newly diagnosed EGPA. Nevertheless, novel biomarkers of activity are more valuable for treated patients with established disease.

Serum eotaxin-3 levels are not clinically useful to measure activity in relapsing EGPA.

EUGENIA S. ZAGVOZDKINA, MD, Clinic of Nephrology, Internal and Occupational Diseases, Sechenov First Moscow State Medical University; SERGEY V. MOISEEV, MD, Clinic of Nephrology, Internal and Occupational Diseases, Sechenov First Moscow State Medical University; PAVEL I. NOVIKOV, MD, Clinic of Nephrology, Internal and Occupational Diseases, Sechenov First Moscow State Medical University, Moscow, Russia. Address correspondence to Prof. S.V. Moiseev, Clinic of Nephrology, Internal and Occupational Diseases, Rossolimo, 11/5,

Moscow 119435, Russia. E-mail: clinpharm@mtu-net.ru

\section{REFERENCES}

1. Jennette JC, Falk RJ, Bacon PA, Basu N, Cid MC, Ferrario F, et al. 2012 revised International Chapel Hill Consensus Conference Nomenclature of Vasculitides. Arthritis Rheum 2013;65:1-11

2. Comarmond C, Pagnoux C, Khellaf M, Cordier JF, Hamidou M, Viallard JF, et al; French Vasculitis Study Group. Eosinophilic granulomatosis with polyangiitis (Churg-Strauss): clinical characteristics and long-term followup of the 383 patients enrolled in the French Vasculitis Study Group cohort. Arthritis Rheum 2013;65:270-81

3. Moosig F, Bremer JP, Hellmich B, Holle JU, Holl-Ulrich K, Laudien $\mathrm{M}$, et al. A vasculitis centre based management strategy leads to improved outcome in eosinophilic granulomatosis and polyangiitis (Churg-Strauss, EGPA): monocentric experiences in 150 patients Ann Rheum Dis 2013;72:1011-7.

4. Novikov P, Moiseev S, Smitienko I, Zagvozdkina E. Rituximab as induction therapy in relapsing eosinophilic granulomatosis with polyangiitis: a report of 6 cases. Joint Bone Spine 2016;83:81-4.

5. Grayson PC, Monach PA, Pagnoux C, Cuthbertson D, Carette S, Hoffman GS, et al; Vasculitis Clinical Research Consortium. Value of commonly measured laboratory tests as biomarkers of disease activity and predictors of relapse in eosinophilic granulomatosis with polyangiitis. Rheumatology 2015;54:1351-9.

6. Polzer K, Karonitsch T, Neumann T, Eger G, Haberler C, Soleiman A, et al. Eotaxin-3 is involved in Churg-Strauss syndrome-a serum marker closely correlating with disease activity. Rheumatology 2008;47:804-8

7. Dejaco C, Oppl B, Monach P, Cuthbertson D, Carette S, Hoffman $\mathrm{G}$, et al. Serum biomarkers in patients with relapsing eosinophilic granulomatosis with polyangiitis (Churg-Strauss). PLoS One 2015;10:e0121737.

8. Stone JH, Hoffman GS, Merkel PA, Min YI, Uhlfelder ML, Hellmann DB, et al; International Network for the Study of the Systemic Vasculitides (INSSYS). A disease-specific activity index for Wegener's granulomatosis: modification of the Birmingham Vasculitis Activity Score. International Network for the Study of the Systemic Vasculitides (INSSYS). Arthritis Rheum 2001;44:912-20.

9. Zwerina J, Bach C, Martorana D, Jatzwauk M, Hegasy G, Moosig F, et al. Eotaxin-3 in Churg-Strauss syndrome: a clinical and immunogenetic study. Rheumatology 2011;50:1823-7.

J Rheumatol 2016;43:11; doi:10.3899/jrheum.160576 